\title{
High-temporal velocity-encoded MRI for the assessment of left ventricular inflow propagation velocity: head-to-head comparison with Color M-mode echocardiography
}

\author{
Emmeline Calkoen ${ }^{1 *}$, Nina Ajmone Marsan ${ }^{2}$, Jeroen J Bax², Pieter J van den Boogaard ${ }^{3}$, Arno Roest ${ }^{1}$, \\ Albert de Roos ${ }^{3}$, Jos J Westenberg ${ }^{3}$
}

From 18th Annual SCMR Scientific Sessions

Nice, France. 4-7 February 2015

\section{Background}

Left ventricular (LV) inflow propagation velocity $(\mathrm{Vp})$ is a useful parameter used in the complex assessment of LV diastolic function and is measured by Color M-mode echocardiography. The aim of current study was to develop an alternative method for $\mathrm{Vp}$-assessment using high-temporal single-directional velocity-encoded Magnetic Resonance Imaging (VE-MRI).

\section{Methods}

43 patients with ischemic heart failure $(61 \pm 11$ years $)$ and

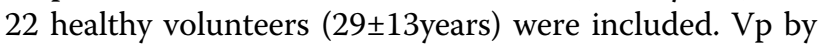
Color M-mode echocardiography (Vp-echo), was measured according to current recommendations (Figure 1). VE-MRI was performed on a 1.5 or 3.0 Tesla MRI system during free breathing, with single-direction in-plane velocity-encoding in phase-encoding direction, angulated parallel to the LV inflow direction. Velocity sensitivity Venc was set to $30 \mathrm{~cm} / \mathrm{s}$ and scan parameters were: spatial resolution $2.5 \times 2.5 \times 8.0 \mathrm{~mm}^{3}$, flip angle $10^{\circ}$, echotime $3.4-3.8 \mathrm{~ms}$ and repetition-time $5.4-5.9 \mathrm{~ms}$. Local LV inflow velocity was sampled along a $4 \mathrm{~cm}$ scan line starting from the tip of the mitral valve and directed into the LV, similarly to the Color M-mode echocardiography; for 11 consecutive sample points equidistantly positioned along the scan line, the point-in-time was assessed when local velocity exceeded $30 \mathrm{~cm} / \mathrm{s}$ (Figure 1 ). From the position-time relation, $\mathrm{Vp}$ was calculated by 2 methods: 1) from the difference quotient between the

'Pediatric cardiology, Leiden University Medical Center, Leiden, Netherlands Full list of author information is available at the end of the article first and the last sample point (Vp-MRI-DQ) and 2) from linear regression from all sample points (Vp-MRI-LR).

\section{Results}

Good correlation was found between $\mathrm{Vp}$-echo and both Vp-MRI-DQ $(r=0.83 \mathrm{p}<0.001)$ and Vp-MRI-LR $(\mathrm{r}=0.84$ $\mathrm{p}<0.001)$. For both Vp-MRI-DQ and Vp-MRI-LR, a significant but small underestimation was observed as compared to Vp measured by Color M-mode echocardiography (Vp-MRI-DQ: $-7.3 \pm 19.7 \mathrm{~cm} / \mathrm{s}, \mathrm{p}=0.004$; Vp-MRI-LR: $-9.9 \pm 15.2 \mathrm{~cm} / \mathrm{s}, \mathrm{p}<0.001)$, with increasing bias for higher $\mathrm{Vp}$ values. Applying age-related cut-off values for $\mathrm{Vp}$ to identify elevated LV filling pressures (Table 1), we observed a Kappa-agreement with echocardiography of $0.72,(\mathrm{p}<0.001)$ for $\mathrm{Vp}-\mathrm{MRI}-\mathrm{DQ}$ and $0.69(\mathrm{p}<0.001)$ for Vp-MRI-LR.

\section{Conclusions}

High-temporal VE-MRI represents a novel approach to assess Vp showing good correlation with Color M-mode echocardiography. In healthy subjects and patients with heart failure, this new method demonstrated good agreement with echocardiography to identify elevated LV filling pressures.

\section{Funding}

E.E. Calkoen is financially supported by a grant from the Willem-Alexander Kinder- en Jeugdfonds, J.J.M. Westenberg is financially supported by a grant from the Dutch Technology Foundation (STW), project number 11626 

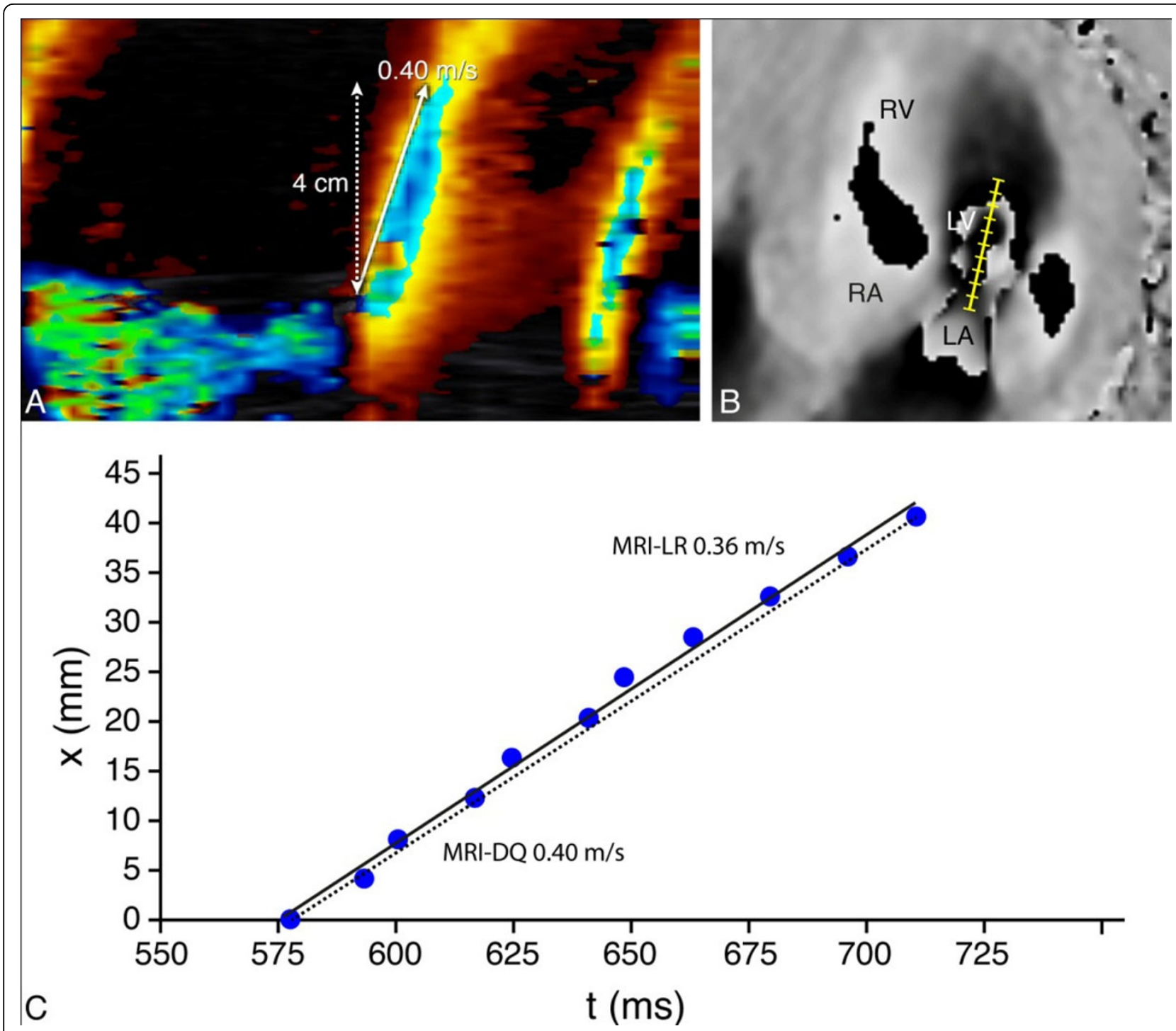

Figure $1 \mathrm{Vp}$ assessment with Color M-mode echocardiography (panel A) and velocity-encoded MRI (panel B). The position-time graph (panel C) with Vp-MRI-Difference-Quotient (dotted line) and Vp-MRI-Lineair-Regression (solid line).

Table 1 Weighted-kappa agreement between Vp-echo and MRI Vp-MRI-DQ and Vp-MRI-LR.

\begin{tabular}{|c|c|c|c|c|c|}
\hline & \multicolumn{2}{|c|}{ Vp-MRI-DQ } & \multicolumn{3}{|c|}{ Vp-MRI-LR } \\
\hline & $\begin{array}{c}<45 / 55 \mathrm{~cm} / \\
\mathrm{s}\end{array}$ & $\begin{array}{c}\geq 45 / 55 \mathrm{~cm} / \\
\mathrm{s}\end{array}$ & $\begin{array}{c}<45 / 55 \mathrm{~cm} / \\
\mathrm{s}\end{array}$ & $\begin{array}{c}\geq 45 / 55 \mathrm{~cm} / \\
\mathrm{s}\end{array}$ & \\
\hline \multirow[t]{2}{*}{$\begin{array}{l}\text { Vp- } \\
\text { echo }\end{array}$} & $\begin{array}{c}<45 / 55 \mathrm{~cm} / \\
\mathrm{s}\end{array}$ & 23 & 6 & 23 & 7 \\
\hline & $\begin{array}{c}\geq 45 / 55 \mathrm{~cm} / \\
\mathrm{s}\end{array}$ & 3 & 33 & 3 & 32 \\
\hline
\end{tabular}

Age-related cut-off values were used to classify elevated LV filling pressures $(\mathrm{Vp}<45 \mathrm{~cm} / \mathrm{s}$ for subjects older than 30 years and $\mathrm{Vp}<55 \mathrm{~cm} / \mathrm{s}$ for subjects younger than 30 years old).

\section{Authors' details}

'Pediatric cardiology, Leiden University Medical Center, Leiden, Netherlands. ${ }^{2}$ Cardiology, Leiden University Medical Center, Leiden, Netherlands.

${ }^{3}$ Radiology, Leiden University Medical Center, Leiden, Netherlands.

Published: 3 February 2015

doi:10.1186/1532-429X-17-S1-Q38

Cite this article as: Calkoen et al:: High-temporal velocity-encoded MRI for the assessment of left ventricular inflow propagation velocity: headto-head comparison with Color M-mode echocardiography. Journal of Cardiovascular Magnetic Resonance 2015 17(Suppl 1):Q38. 